\title{
Using digital multimedia to improve parents' and children's understanding of clinical trials
}

\author{
Alan R Tait, ${ }^{1,2}$ Terri Voepel-Lewis, ${ }^{1}$ Robert Levine ${ }^{3,4}$
}

${ }^{1}$ Department of

Anesthesiology, University of

Michigan Health System, Ann

Arbor, Michigan, USA

${ }^{2}$ Center for Bioethics and

Social Sciences in Medicine,

University of Michigan

${ }^{3}$ Emergency Care Center, Jackson Memorial Hospital,

Miami, Florida, USA

${ }^{4}$ ArchieMD, Inc., Boca Raton,

Florida, USA

\section{Correspondence to}

Dr Alan R Tait, Department of Anesthesiology, University of Michigan Health System, 1500 E. Medical Center Drive, Ann Arbor, MI 48109, USA; atait@umich.edu

Received 4 December 2014 Revised 2 March 2015 Accepted 8 March 2015 Published Online First 31 March 2015

\begin{abstract}
Objective Data show that many research subjects have difficulty understanding study information using traditional paper consent documents. This study, therefore, was designed to evaluate the effect of an interactive multimedia program on improving parents' and children's understanding of clinical trial concepts and participation.

Methods Parents $(n=148)$ and children $(n=135)$ were each randomised to receive information regarding clinical trials using either a traditional paper format (TF) or an interactive iPad program (IP) with inline exercises. Participants' understanding of the information was assessed using semistructured interviews prior to (pretest) and after (post-test) receiving the information. Participants also completed a short survey to assess their perceptions of information delivery and satisfaction with the process.
\end{abstract}

Results Regardless of the mode of information delivery, all participants demonstrated improved pretest to posttest understanding. While there were no statistical differences in parents' post-test understanding between the TF and IP groups, children in the IP group had significantly greater post-test understanding compared with children in the TF group (11.65 (4.1) vs 8.85 (4.1) $(2.8,1.4,4.2) 0-18$ scale where $18=$ complete understanding). Furthermore, the IP was found to be significantly 'easier to follow' and 'more effective' in presenting information compared with the TF.

Conclusions Results demonstrated the importance of providing information regarding clinical trial concepts to parents and children. Importantly, the ability of interactive multimedia to improve understanding of clinical trial concepts and satisfaction with information delivery, particularly among children, supports this approach as a novel and effective vehicle for enhancing the informed consent process.

\section{INTRODUCTION}

Informed consent is central to the bioethical principle of respect for persons, yet many studies have shown that research participants do not understand the information they are given and, as such, have difficulty making informed decisions. ${ }^{1-4}$ In one cancer trial, less than half of participants were able to recall the risks and the unproven nature of the trial, ${ }^{5}$ and in a neuro-oncology study, 29\% of participants were unable to recall any risks of the trial drug. ${ }^{6}$ Clinical trials should neither create false hopes nor a sense of futility $^{7}$ yet, therapeutic misconception (belief that the study is an extension of standard treatment) is common. ${ }^{8} 9$ Furthermore, many central concepts of clinical trials such as randomisation and blinding are often misunderstood. ${ }^{8-11}$

\section{What is already known on this topic?}

- As the number of paediatric clinical trials has increased, so too has the amount and complexity of the information provided.

- Many parents and children have difficulty understanding the information provided to them and often struggle to make informed decisions.

\section{What this study adds?}

- To date, few alternatives to the traditional paper consent document for research and treatment exist.

- Results from this study suggest that interactive digital multimedia may be useful in helping children better understand clinical trial information and enhancing informed decision-making.

Paediatric clinical trials may pose greater challenges compared with adult trials. Parents and adolescents, for example, may have different appreciation and understanding of the risks and benefits of a clinical trial and differ in opinions regarding decision-making authority and physician influence. ${ }^{12}$ In one study, adult oncology decisionmakers were more informed and engaged by their physicians compared with parent decisionmakers. ${ }^{13}$ Parents and children also struggle with concepts such as randomisation and often confuse the different phases of trial development. ${ }^{13} 14$ This is important given that a lack of understanding of these important concepts and confusion between research and treatment undermines the central basis for informed consent. Furthermore, subjects who do not understand study information may misinterpret the risks and benefits, be unable to follow a research protocol and may ultimately regret participating. $^{2}$

Growing evidence suggests that interactive computer-based digital information may provide greater patient comprehension of medical information compared with the more traditional paper formats (TFs) ${ }^{15-18}$ but there is little data to support this approach for research. This study therefore, was designed to compare parents' and children's understanding of clinical trial information delivered using either an interactive multimedia program or a TF. 


\section{METHODS}

A waiver of written consent/assent was obtained. Participants consisted of parents ( $>18$ years) and children (10-17 years) attending one of several paediatric clinics. Exclusion criteria included non-English speakers and those with cognitive impairment. Demographics including age, gender, education and race/ ethnicity were recorded. Subject literacy was measured using the Slosson Oral Reading Test-revised. ${ }^{19}$

\section{Digital program development}

Computer-visualisations were modelled using two-dimensional and three-dimensional graphics software and merged into modules that described the clinical trial concepts. Using an iPad platform, information was presented in visual and written formats together with a narrative 'voice-over'. Screens were presented sequentially and could not be skipped. An example screenshot that uses a pictograph to describe the chance of receiving the experimental treatment in a clinical trial is shown in figure 1 . The program also included five interactive exercises that participants were required to complete in order to advance. These exercises required participants to 'point and touch' or 'touch and drag' on the screen to select their responses. One exercise required participants to solve a jigsaw puzzle by matching a term with the correct answer. Each exercise employed corrective feedback (coloured icons or sound) to inform the participant as to whether or not they had correctly answered the questions.

The paper version contained text only but the content was identical to that presented in the digital version, however, no exercises were included. Written information in both versions was written at the 7 th- 8 th grade reading level (Flesch-Kincaid reading formula). ${ }^{20}$

\section{Evaluation}

Consecutive parents and children were recruited in the outpatient clinic and each given a short pretest to elicit their understanding of nine basic research concepts, that is, clinical trial, participation, protocol, randomisation, placebo, blinding, double-blinding, effectiveness and informed consent. Participants' responses were written down verbatim by a trained research assistant who had no

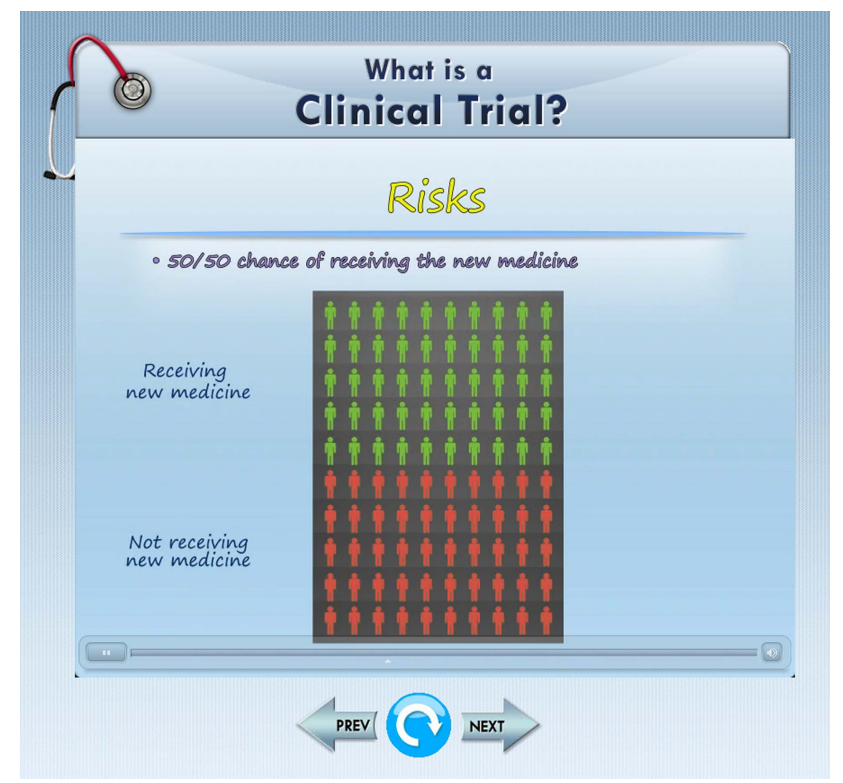

Figure 1 Screenshot highlighting the probability of being randomised to the treatment or control arms of a clinical trial. vested interest in the study. Participants were then randomised (computer-generated) to receive information about these clinical trial concepts and participation using either a TF or the digital interactive program (IP). Parents and children were evaluated separately to ensure individualised responses.

Once the participants completed the TF or IP, they were interviewed a second time to determine their 'new' understanding of the information (post-test). This post-test was identical to the pretest. In addition, participants were also interviewed to test their knowledge of different aspects of clinical trial participation (seven items, eg, "what are the possible good things that might happen to you (or your child) by being in a clinical trial?") All tests were scored independently by two blinded assessors based on criteria established prior to the study and using a three-point scale of 'no understanding' (0), 'partial understanding' (1) and 'complete understanding' (2). Thus, scores on the tests ranged from 0-18 (concepts) and 0-14 (participation). In scoring, children were not expected to provide the same amount of detail as parents. This process of interviewing and scoring has been described previously. ${ }^{4} 2122$

For the IP group, the ability to correctly answer questions (first or subsequent attempts) in the inline exercises was recorded. Additionally, a survey related to the participants' perceptions of, and satisfaction with the quality and effectiveness of the information was conducted using a combination of $0-10$ numbers scales and Likert scales. At the end of the study, participants were shown the TF and IP information and asked which they preferred.

\section{Statistical analysis}

Statistical analyses were performed using SPSS V.21.0 (IBM Corp, New York, New York, USA) software. Within-group and between-group pretests and post-tests were analysed for parametric and non-parametric data. Categorical variables were analysed using $\chi^{2}$ or Fisher's exact tests. A linear regression analysis was performed with forced variable entry to identify independent predictors of post-test comprehension. Inter-rater agreements between assessors' scores were performed on approximately $12 \%$ of the population using the $\kappa$ statistic for all the concepts tested. $\kappa$ values of $\geq 0.7$ were considered acceptable. Results ranged from 0.77 to $1.0(\mathrm{p}<0.001)$. Data are $\mathrm{m}(\mathrm{SD})$ and $\mathrm{n}(\%)$.

\section{Sample size}

Parents

Power analysis was based on a previous study in which parental understanding of a standard consent was 8.1 (2.3) (scale of 0-12) compared with $9.3(2.2)$, when using a computer program. ${ }^{18}$ Accepting this difference as the smallest difference deemed clinically important, we required a sample of $73 /$ group $(\alpha=0.05$, $\beta=0.1$, two-sided).

\section{Children}

Sample size was based on previous studies which showed that children's understanding of standard assent information was 3.7 (3.3) (scale of $0-10$ ) and that understanding of research information using an interactive consent program was approximately 50\% greater. ${ }^{17} 23$ Accepting this difference as clinically important, we required a sample of $67 /$ group ( $\alpha=0.05, \beta=0.1$, two-sided).

\section{RESULTS}

A total of 278 parents and 186 children were approached to participate. Of these, 130 parents and 51 children declined participation. The primary reason for declining was a perceived lack of time to complete the assessments (46.9\%). Other 
Table 1 Parent and child demographics

\begin{tabular}{|c|c|c|}
\hline & TF & IP \\
\hline \multicolumn{3}{|l|}{ Age (years): } \\
\hline Parents & $40.1(11.8)$ & $42.0(10.9)$ \\
\hline Children & $13.2(1.8)$ & $13.4(2.3)$ \\
\hline \multicolumn{3}{|l|}{ Gender (F): } \\
\hline Parents & $46(62.2)$ & $52(71.2)$ \\
\hline Children & $34(50.0)$ & $33(50.0)$ \\
\hline \multicolumn{3}{|l|}{ Parents' race/ethnicity: } \\
\hline White & $57(77.0)$ & $53(74.6)$ \\
\hline African-American & $13(17.6)$ & $13(18.3)$ \\
\hline Hispanic & $3(4.1)$ & $0(0.0)$ \\
\hline Other & $1(1.4)$ & $5(7.0)$ \\
\hline \multicolumn{3}{|l|}{ Education: } \\
\hline \multicolumn{3}{|l|}{ Parents } \\
\hline$\leq$ High school & $23(31.1)$ & $18(24.7)$ \\
\hline Some college & $23(31.1)$ & $18(24.7)$ \\
\hline$\geq$ College graduate & $28(37.8)$ & $37(50.6)$ \\
\hline Children school grade: median (range) & $8(4-11)$ & $8(4-12)$ \\
\hline \multicolumn{3}{|l|}{ Previous research participation } \\
\hline Parents & $23(30.7)$ & $15(20.5)$ \\
\hline Children & $6(8.7)$ & $13(19.7)$ \\
\hline \multicolumn{3}{|l|}{ SORT-R3: } \\
\hline Parents & $184.5(27.9)^{*}$ & $182.5(26.9)^{*}$ \\
\hline Children & $155.8(29.1) \dagger$ & $155.9(35.1) \dagger$ \\
\hline \multicolumn{3}{|c|}{$\begin{array}{l}\text { Data are presented as mean (SD) or } n(\%) \text {. } \\
{ }^{*} \text { Approximates } 10 \text { th grade reading ability. } \\
\text { †Approximates } 7.0 \text { grade reading ability. } \\
\text { TF, traditional paper format; IP, interactive digital program; SORT-R3, Slosson Oral } \\
\text { Reading Test Revised. }\end{array}$} \\
\hline
\end{tabular}

reasons included a lack of interest, poor English and 'no reason.' One child was deemed ineligible after enrolment (age criterion) and was withdrawn from analysis. Complete data were thus, available for 148 parents and 135 children.

Participant demographics are described in table 1. As shown, there were no differences in sociodemographics between the TF and IP groups for parents and children.

Table 2 describes the parents' and children's precomprehension and postcomprehension of clinical trial concepts and their understanding of clinical trial participation. As shown, parents' and children's baseline understanding was generally poor.
There were no statistically significant differences in understanding between parents in the TF and IP groups. On the other hand, while children in both groups showed increased post-test comprehension, these improvements were significantly greater among children randomised to the IP group. Overall, children in the 8 th grade (approximately 12-13 years) or higher had better understanding compared with children in the lower grades although this difference was only significant for the IP group (10.3 (4.2) vs 6.96 (3.3), 0-18 scale, $\mathrm{p}<0.01$ ).

A linear regression analysis using children's post-test comprehension of clinical trial concepts as the dependent variable and age, grade level and group assignment as the independent variables identified exposure to the IP $(B=2.44, p=0.001)$ and being in the 8 th grade or higher $(B=1.60, p=0.015)$ as independently predictive.

Table 3 describes changes between the pretest and post-test measures of understanding of the individual clinical trial concepts. These data are important in highlighting which concepts were poorly understood at baseline and which responded best to the interventions.

Table 4 describes the participants' perceptions of the information delivery. As shown, children and parents randomised to the IP group perceived the information to be significantly easier to follow, clearer and more effective compared with those receiving the TF.

Overall satisfaction with iPad graphics and interactivity ranged from 8.59 (1.5) to 9.58 (0.7) out of 10 (where $10=$ extremely satisfied). When shown both formats, $67.9 \%$ of children and $62.4 \%$ of parents reported that they preferred the IP. When asked how they would prefer to receive information if recruited for a future study, all participants reported a preference for digital information.

Results of the inline exercises indicated that parents and children showed moderate to excellent real-time understanding of the information. For example, when asked to select from a number of options, $72.2 \%$ of parents and $71.2 \%$ of children correctly selected 'double-blind means that neither the patient nor the doctor knows who is getting the new treatment'.

\section{DISCUSSION}

Results from this study showed that parents' and children's baseline understanding of clinical trial concepts was generally poor. These results are in accordance with other studies showing poor understanding of commonly used research terms such as

Table 2 Preunderstanding and postunderstanding by information delivery

\begin{tabular}{|c|c|c|c|}
\hline & TF & IP & Mean difference $(95 \% \mathrm{CI})$ \\
\hline Children & $\mathrm{n}=68$ & $\mathrm{n}=67$ & \\
\hline Pretest understanding of concepts $†$ & $3.97(2.7)$ & $3.76(2.6)$ & $-0.2(-1.1$ to 0.7$)$ \\
\hline Post-test understanding of concepts† & $8.85(4.1)$ & $11.65(4.1)$ & $2.8(1.4 \text { to } 4.2)^{*}$ \\
\hline$\Delta$ Pre-post understanding of conceptst & $4.88(3.4)$ & $7.84(3.1)$ & $3.0(1.8 \text { to } 4.1)^{*}$ \\
\hline Post-test understanding of research participation $\ddagger$ & $12.39(2.8)$ & $15.86(2.9)$ & $3.5(2.4 \text { to } 4.6)^{*}$ \\
\hline Parents & $\mathrm{n}=75$ & $\mathrm{n}=73$ & \\
\hline Pretest understanding of conceptst & $7.67(3.9)$ & $7.90(4.1)$ & $0.66(-1.1$ to 1.5$)$ \\
\hline Post-test understanding of conceptst & $12.71(4.0)$ & $13.34(3.6)$ & $0.64(-0.6$ to 1.9$)$ \\
\hline$\Delta$ Pre-post understanding of conceptst & $5.04(3.3)$ & $5.43(3.5)$ & $0.39(-0.7$ to 1.5$)$ \\
\hline Post-test understanding of research participation $\ddagger$ & $16.64(2.4)$ & $17.36(2.6)$ & $0.72(-1.5$ to 1.6$)$ \\
\hline
\end{tabular}

Data are presented as mean (SD) and $n(\%)$.

$\Delta=$ Pre-post change in understanding.

${ }^{*} \mathrm{p}<0.001$.

t0-18 scale where $18=$ complete overall understanding

$\neq 0-14$ scale where $14=$ complete overall understanding

IP, interactive digital program; TF, traditional paper format. 
Table 3 Percentage of participants having no understanding of clinical trial concepts: pretest versus post-test

\begin{tabular}{|c|c|c|c|c|}
\hline & \multicolumn{2}{|l|}{ Children } & \multicolumn{2}{|l|}{ Parents } \\
\hline & TF & IP & TF & IP \\
\hline \multicolumn{5}{|l|}{ Clinical trial } \\
\hline Pre & $46(66.7)$ & $44(67.7)$ & $22(29.3)$ & $22(30.1)$ \\
\hline Post & $19(27.5)$ & $14(21.2)$ & $11(14.7)$ & $5(6.8)$ \\
\hline$\Delta$ Pre-post & 39.2 & 46.5 & 14.6 & 23.3 \\
\hline \multicolumn{5}{|l|}{ Randomisation } \\
\hline Pre & $38(55.1)$ & 27 (41.5) & $44(58.7)$ & $33(45.2)$ \\
\hline Post & $23(33.3)$ & $12(18.2)^{*}$ & $19(25.3)$ & $11(15.1)$ \\
\hline$\Delta$ Pre-post & 21.8 & 23.3 & 33.4 & 30.1 \\
\hline \multicolumn{5}{|l|}{ Placebo } \\
\hline Pre & $61(88.4)$ & $58(89.2)$ & $24(32.0)$ & $25(34.2)$ \\
\hline Post & $38(55.1)$ & $6(9.1)^{*}$ & $10(13.3)$ & $6(8.2)$ \\
\hline$\Delta$ Pre-post & 33.3 & 80.1 & 18.7 & 26.0 \\
\hline \multicolumn{5}{|l|}{ Single blinding } \\
\hline Pre & 67 (98.6) & 64 (98.5) & $49(65.3)$ & $44(61.1)$ \\
\hline Post & $32(46.4)$ & $12(18.2)^{*}$ & $11(14.7)$ & $6(8.2)$ \\
\hline$\Delta$ Pre-post & 52.2 & 80.3 & 50.6 & 52.9 \\
\hline \multicolumn{5}{|l|}{ Double blinding } \\
\hline Pre & 67 (98.6) & $64(98.5)$ & $56(74.7)$ & $55(75.3)$ \\
\hline Post & $33(47.8)$ & $9(13.6)^{*}$ & $11(14.7)$ & $10(13.7)$ \\
\hline$\Delta$ Pre-post & 50.8 & 84.9 & 60.0 & 61.6 \\
\hline \multicolumn{5}{|c|}{ Informed consent } \\
\hline Pre & $27(39.1)$ & $35(53.8)$ & $9(12.0)$ & $8(11.0)$ \\
\hline Post & $21(30.4)$ & $28(42.4)$ & $5(6.7)$ & $3(4.1)$ \\
\hline$\Delta$ Pre-post & 8.7 & 11.4 & 5.3 & 6.9 \\
\hline
\end{tabular}

randomisation and placebo. ${ }^{10} 1124$ The reasons for this are multifactorial but are due in part to the fact that investigators either do not explain the terms and/or that consent forms have become overly complex. In one study, Kodish et $a l^{25}$ showed that randomisation was not explained by $17 \%$ of physicians involved in paediatric leukaemia trials and that $50 \%$ of parents did not understand the term. This lack of understanding likely plays a role in the concept of 'therapeutic misconception' wherein participants confuse treatment with research and are often unaware that group allocation occurs by chance. ${ }^{24} 26$ Difficulties were also observed with other concepts; for example, one participant believed that a placebo was 'a part of the body' and another defined double-blinding as 'two clinical trials where two children are blind, maybe twins.' Despite this, the results show that providing information improved parents' and children's comprehension and thus, reinforced the importance of explaining not just the details of a study but also the terms used. Clearly, if these basic terms are not understood, it is not surprising that many participants have difficulty understanding more complex issues involving risk-benefit trade-offs.

Important was the observation that children in the IP group had significantly greater comprehension of trial concepts and participation compared with children receiving the TF. The theory behind this observation is grounded in the so-called pictorial superior effect which posits that information provided in pictorial format is easier to understand and requires less cognitive effort compared with text. ${ }^{27-29}$ Furthermore, data suggest that interactive programs enhance understanding because they promote active learning. ${ }^{27-31}$ However, given the known benefits of the pictorial superior effect, it is unclear as to why parents did not enjoy the same parallel increase in comprehension with the IP. Although the data suggest trends towards quantitatively greater understanding among parents in the IP group, these were not statistically significant. This is surprising given that recent studies show that interactive computer-based multimedia programs increase patient understanding of treatment information compared with standard text. ${ }^{18} 22$ One possible explanation is that because our parent population was skewed towards those with good education and literacy, any potential positive impact of the IP on understanding appeared less pronounced. It may also reflect the current generation's facility with digital media. That being said, the majority of parents and children perceived the digital information to be easy to follow, very clear and effective as a means of information delivery. Furthermore, the iPad program was deemed easy to use and satisfaction with the digital format was uniformly high. When shown the TF and IP formats, the majority of parents and children reported that they preferred the IP, suggesting greater acceptance of this technology as a means to convey information.

The use of exercises with corrected feedback has been shown to be effective in promoting retention of information. ${ }^{32} 33$ Given that longer-term retention of information is typically poor, this approach allows the investigator to assess understanding at the time decisions are actually made. These exercises are also useful in identifying problem areas and in directing investigator efforts towards targeted discussion. The interactive nature of these exercises is also important as a means to promote active learning and promote understanding ${ }^{22}$ 34-36 and may explain, in part, why children appeared to perform equally well as parents on the inline exercises. Recently, we showed that patients who performed better in inline exercises regarding their cardiac catheterisation also had better overall understanding of the procedure. $^{22}$

Table 4 Perceptions of the information delivery

\begin{tabular}{|c|c|c|c|c|}
\hline & \multicolumn{2}{|l|}{ Children } & \multicolumn{2}{|l|}{ Parents } \\
\hline & TF & IP & TF & IP \\
\hline Information quality $n$ (SD) & $8.22(1.6)$ & $8.68(1.4)$ & $9.01(1.2)$ & $9.39(1.0)^{*}$ \\
\hline Ability to follow information $n$ (SD) & $7.27(1.8)$ & $8.16(1.8)^{*}$ & $8.78(1.6)$ & $9.27(1.1)^{*}$ \\
\hline Effectiveness of presentation: 'Extremely effective' n (\%) & $29(42.0)$ & $45(68.2)^{*}$ & $56(74.7)$ & $67(91.8)^{*}$ \\
\hline Amount of information: 'Just right' n (\%) & $60(87.0)$ & $65(98.5)^{*}$ & $69(92.0)$ & $68(93.2)$ \\
\hline Clarity of information: 'Very clear' n (\%) & $28(40.6)$ & $48(72.7)^{*}$ & $62(82.7)$ & $62(84.9)$ \\
\hline
\end{tabular}


Limitations to this study are acknowledged. First, we fully recognise that the requirements for assent are different from those of parental permission and thus children would not necessarily be expected to understand all the concepts provided. ${ }^{37}{ }^{38} \mathrm{In}$ general, children are only required to understand the purpose of the study, what will happen to them, and that their participation is voluntary. However, studies ${ }^{49}$ suggest that some children are able to understand information beyond these basic elements and, importantly to that end, these results highlight the potential of interactive multimedia to help children do so. Second, this study represents one intervention at one institution. Given that the patient population at the University of Michigan is relatively educated and predominantly White, these results may not be generalisable to all patient populations.

In summary, this study emphasised the importance of providing parents and children with information to help them understand important clinical trial terms/concepts as well as their role as research subjects. Of note was that among children, the use of digital information resulted in a significant increase in understanding compared with the TF. This suggests that this approach may be a better way of actively engaging children in a manner that is familiar to them and which can enhance their ability to provide assent. Although this finding was not observed to the same extent among parents, it is worth noting that all participants found the IP to be more effective in presenting information compared with the TF and reported that they would prefer digital formats as a vehicle for receiving future research information. These results, therefore, support the use of interactive digital multimedia as a means to help research participants, particularly children, understand the fundamental aspects of clinical trials and thus, provide an important platform for shared informed decision-making.

Acknowledgements The authors thank Tara van Veen for subject recruitment and data collection.

Contributors ART conceptualised and designed the study, performed the statistical analyses and wrote and approved all drafts of the manuscript. TV-L coordinated and supervised data collection, reviewed and revised the manuscript, and approved the final version as submitted. RL directed development of the interactive program, critically reviewed the manuscript and approved the final version as submitted.

Funding This work was supported by a grant from the NIH (NHLBI, HHSN268201200043C).

Competing interests RL is the President and Chief Medical Officer of ArchieMD. but was funded independently for this project by a grant from the National Institutes of Health. RL was responsible for the development of the interactive iPad program and read the final manuscript but had no involvement in subject recruitment, data collection, scoring, statistical analysis or interpretation of the data. None of the other investigators have any financial or commercial interests in ArchieMD. or other conflicts of interest to declare.

Ethics approval Approved by the University of Michigan's Institutional Review Board.

Provenance and peer review Not commissioned; externally peer reviewed.

\section{REFERENCES}

1 Barrett R. Quality of informed consent: measuring understanding among participants in oncology clinical trials. Oncol Nurs Forum 2005;32:751-5.

2 Stryker J, Wray R, Emmons K, et al. Understanding the decisions of cancer clinical trial participants to enter research studies: Factors associated with informed consent, patient satisfaction, and decisional regret. Patient Educ Counsel 2005;63:104-9.

3 Tait AR, Voepel-Lewis T, Malviya S. Do they understand? (Part I): parental consent for children participating in clinical anesthesia and surgery research. Anesthesiology 2003;98:603-8.

4 Tait AR, Voepel-Lewis T, Malviya S. Do they understand? (Part II): assent of children participating in clinical anesthesia and surgery research. Anesthesiology 2003;98:609-14.

5 Bergenmar M, Molin C, Brandberg Y. Knowledge and understanding among cancer patients consenting to participate in clinical trials. Eur J Cancer 2008;44:2627-33.
6 Knifed E, Lipsam N, Mason W, et al. Patients' perception of the informed consent process for neurooncology clinical trials. Neuro Oncol 2008;10:348-54.

7 Daugherty C. Impact of therapeutic research on informed consent and the ethics of clinical trials: A medical oncology perspective. I Clin Oncol 1999;17:1601-17.

8 Henderson G, Davis A, King N, et al. Uncertain benefits: investigators' views and communications in early phase gene transfer trials. Mol Ther 2004;10:225-31.

9 Kimmelman J, Palmour N. Therapeutic optimism in the consent forms of phase 1 gene transfer trials: an empirical analysis. J Med Ethics 2005;31:209-14.

10 Featherstone K, Donovan J. Random allocation or allocation at random? Patients' perspectives of participation in a randomised controlled trial. BMJ 1998;317:1177-80.

11 Featherstone K, Donovan J. "Why don't they just tell me straight, why allocate it?" The struggle to make sense of participating in a randomised controlled trial. Soc Sci Med 2002;55:709-19.

12 Scherer $D$, Annett $R$, Brody J. Ethical issues in adolescent and parent informed consent for pediatric asthma research participation. J Asthma 2007;44:489-96.

13 Simon C, Siminoff L, Kodish E, et al. Comparison of the informed consent process for randomized clinical trials in pediatric and adult oncology. J Clin Oncol 2004;22:2708-17.

14 Barfield R, Church C. Informed consent in pediatric clinical trials. Curr Opin Pediatr 2005;17:20-4.

15 Hermann M. 3-dimensional computer animation-a new medium for supporting patient education before surgery. Acceptance and assessment of patients based on prospective randomized study — picture versus text [German]. Chirug 2002;73:500-7.

16 Hopper K, Zajdel M, Hulse S, et al. Interactive method of informing patients of the risks of intravenous contrast media. Radiology 1994;192:67-71.

17 Tait AR, Voepel-Lewis T, McGonegal M, et al. Evaluation of a prototype interactive consent program for pediatric clinical trials: a pilot study. JAMIA 2012;19:e43-5.

18 Tait AR, Voepel-Lewis T, Moscucci M, et al. Patient comprehension of an interactive, computer-based information program for cardiac catheterization. Arch Intern Med 2009;169:1907-14.

19 Slosson R. Slosson oral reading test-revised. East Aurora, NY: Slosson Educational Publications, 1990.

20 Flesch R. A new readability yardstick. J Appl Psychol 1948;32:2211-23.

21 Miller $C, O^{\prime}$ Donnell $D$, Searight $H$, et al. The Deaconess Informed Consent Comprehension Test: an assessment tool for clinical research subjects. Pharmacotherapy 1996;16:872-8.

22 Tait AR, Voepel-Lewis T, Chetcuti S, et al. Enhancing patient understanding of medical procedures: evaluation of an interactive multimedia program with in-line exercises. Int J Med Inform 2014;83:376-84.

23 Tait AR, Voepel-Lewis T, Malviya S. Presenting research information to children: a tale of two methods. Anesth Analg 2007;105:358-64.

24 Snowdon C, Garcia J, Elbourne D. Making sense of randomization; responses of parents of critically ill babies to random allocation of treatment in a clinical trial. Soc Sci Med 1997:45:1337-55.

25 Kodish E, Murray T, Shurin S. Cancer risk research: what should we tell subjects? Clin Res 1994;42:396-402.

26 Appelbaum P, Roth L, Lidz C, et al. False hope and best data: consent to research and the therapeutic misconception. Hastings Cent Rep 1987:17:20-4.

27 Ally B, Budson A. The worth of pictures: using high density event-related potentials to understand the memorial power of pictures and the dynamics of recognition memory. Neuroimage 2007;35:378-95.

28 Cherry K, Park D, Frieske $D$, et al. Verbal and pictorial elaborations enhance memory in younger and older adults. Aging Neuropsychol Cogn 1996;3:15-29.

29 Hockley W. The picture superiority effect in associatve recognition. Memory Cogn 2008;36:1351-9.

30 Morris $D$, Rothera M. The application of computer-enhanced imaging to improve preoperative counselling and informed consent in children considering bone anchored auricular prosthesis surgery. Int I Pediatr Otorhinolaryngol 2000;55:181-6.

31 Shaw M, Beebe T, Tomshine P, et al. A randomized, controlled trial of interactive, multimedia software for patient colonoscopy education. J Clin Gastroenterol 2001:32:142-7.

32 Festinger D, Dugosh K, Croft J, et al. Corrected feedback: a procedure to enhance recall of informed consent to research among substance abusing offenders. Ethics Behav 2010;20:387-99.

33 Kang $H$, McDermott $B$, Roediger $H$. Test format and corrective feedback modify the effect of testing on long-term retention. Eur J Cogn Psychol 2007;19:528-58.

34 Schank R. Active learning through multimedia. IEEE Multimedia 1994;1:69-78.

35 Schrand T. Tapping into active learning and multiple intelligences with interactive multimedia: A low-threshold classroom approach. Coll Teach 2008;56:78-84.

36 Zhang D. Interactive multimedia-based E-learning: a study of effectiveness. Am J Distance Learn 2005;19:149-62.

37 Nelson R, Reynolds W. Child assent and parental permission: a comment on Tait's "Do they understand?" Anesthesiology 2003;98:597-8.

38 Sibley A, Sheehan M, Pollard A. Assent is not consent. J Med Ethics 2012;38:3.

39 Hein I, Troost P, Lindeboom R, et al. Accuracy of the MacArthur Competence Assessment tool for clinical research (MacCAT-CR) for measuring children's competence to consent to clinical research. JAMA Pediatr 2014;168:1147-53. 